\title{
Nontidal ocean loading: amplitudes and potential effects in GPS height time series
}

\author{
T. van Dam - X. Collilieux - J. Wuite - Z. Altamimi . \\ J. Ray
}

Received: 21 February 2011 / Accepted: 10 April 2012

(C) The Author(s) 2012. This article is published with open access at Springerlink.com

\begin{abstract}
Ocean bottom pressure (OBP) changes are caused by a redistribution of the ocean's internal mass that are driven by atmospheric circulation, a change in the mass entering or leaving the ocean, and/or a change in the integrated atmospheric mass over the ocean areas. The only previous global analysis investigating the magnitude of OBP surface displacements used older OBP data sets (van Dam et al. in J Geophys Res 129:507-517, 1997). Since then significant improvements in meteorological forcing models used to predict OBP have been made, augmented by observations from satellite altimetry and expendable bathythermograph profiles. Using more recent OBP estimates from the Estimating the Circulation and Climate of the Ocean (ECCO) project, we reassess the amplitude of the predicted effect of OBP on the height coordinate time series from a global distribution of GPS stations. OBP-predicted loading effects display an RMS scatter in the height of between 0.2 and $3.7 \mathrm{~mm}$, larger than previously reported but still much smaller (by a factor of 2) than the scatter observed due to atmospheric pressure loading. Given the improvement in GPS hardware and data analysis techniques, the OBP signal is similar to the precision of weekly GPS height coordinates. We estimate the
\end{abstract}

T. van Dam $(\varangle) \cdot J$. Wuite

Faculty of Science, Technology, and Communication,

Research Unit of Engineering Sciences,

University of Luxembourg, 6 rue Richard Coudenhove-Kalergi,

1359 Luxembourg, Luxembourg

e-mail: tonie.vandam@uni.lu

X. Collilieux $\cdot$ Z. Altamimi

Institut Géographique National (IGN)/Laboratoire

de Recherche en Godsie (LAREG) and Groupe de Recherche en

Géodésie spatiale (GRGS), 6-8 Avenue Blaise Pascal,

77455 Champs-sur-Marne, France

J. Ray

NOAA National Geodetic Survey, Silver Spring, MD 20910, USA effect of OBP on GPS height coordinate time series using the MIT reprocessed solution, mil. When we compare the predicted OBP height time series with mil, we find that the scatter is reduced over all stations by $0.1 \mathrm{~mm}$ on average with reductions as high as $0.7 \mathrm{~mm}$ at some stations. More importantly we are able to reduce the scatter on $65 \%$ of the stations investigated. The annual component of the OBP signal is responsible for $80 \%$ of the reduction in scatter on average. We find that stations located close to semi-enclosed bays or seas are affected by OBP loading to a greater extent than other stations.

Keywords Loading effects - Ocean bottom pressure . Height coordinate time series $\cdot$ Annual signals

\section{Introduction}

In many instances, the primary parameter of interest from a time series of Global Navigation Satellite System (GNSS) or global positioning system (GPS) station coordinates is the long-term trend. For example, GNSS trends of vertical station position are used to quantify processes such as glacial isostatic rebound (for a comprehensive review on this topic see King et al. 2010), sea-level rise (for a comprehensive review see Blewitt et al. 2010), present day ice-mass change (Khan et al. 2010a,b), and inflation and deflation of calderas (Ji and Herring 2011; Chang et al. 2007; Tizzani et al. 2007). For these signals, the trends determined from short times series (less than 3 years) are often the same order of magnitude as the uncertainty on the trend. One way to reduce this uncertainty is with long observation times. Another solution, is to reduce or eliminate the noise and unwanted signal in the data.

Time variable changes in the mass distribution of the atmosphere and continental water, load and displace the surface 
of the Earth to such an extent that they are observable in geodetic coordinate time series (van Dam and Herring 1994; van Dam et al. 1994, 1997, 2001; Zerbini et al. 2004; Schuh et al. 2003; Scherneck et al. 2002; Petrov and Boy 2004; Tregoning et al. 2009; Tesmer et al. 2011; Lavallée et al. 2010). Tidal and nontidal ocean mass changes also load the Earth's surface. The tidal component of ocean loading is routinely removed from space geodetic data already. Recommendations for modeling this signal are provided by the International Earth Rotation and Reference Systems Service (IERS) conventions (Petit and Luzum 2010). Nontidal ocean mass variations, however, also exist and can also displace the Earth's surface at a level that should be observable in GPS coordinate data. These ocean bottom pressure (OBP) changes are caused by the following processes: (1) the internal mass redistribution of the ocean driven by atmospheric circulation; (2) water mass entering or leaving the ocean (e.g. the global water cycle) (Chambers et al. 2004); (3) a change in the integrated atmospheric mass over the ocean areas (Ponte 1999).

In Fig. 1, we show the root-mean-scatter (RMS) (top panel) and the maximum peak-to-peak changes (bottom panel) of the predicted radial surface displacement (in the center of figure reference frame) due to OBP loading computed at every $2.5^{\circ}$ of latitude and longitude over the globe. (Note the difference in scale between the top and bottom panels.) The results were determined using 5 years of the OBP product derived from the Estimating the Circulation and Climate of the Ocean (ECCO) project (The ECCO OBP product will be described in more detail in the next section). The largest scatter and the greatest amplitudes of the crustal displacement are found in the region of the Antarctic Circumpolar Current (ACC). In the ECCO model, these signals are driven by variable wind stress curl, zonal winds and changes in ACC transport (see Ponte 1999; Stepanov and Hughes 2006). In the interior of continents, where the majority of geodetic positioning stations are located, the scatter is usually less than $1 \mathrm{~mm}$ with maximum predicted displacements only reaching $3 \mathrm{~mm}$. However, at some coastal locations, particularly regions near the Aleutians, the British Isles, and the east coasts of Asia, Australia, and North and South America, the scatter in the height can exceed $6 \mathrm{~mm}$ with maximum displacements well over $10 \mathrm{~mm}$. Most of these coastal regions are near semi-enclosed seas and bays or oceanic regions where the redistribution of water due to wind or atmospheric pressure forcing is hindered by the local coastal geometry and bathymetry. Storm surges, which are not considered here, can raise coastal water levels to such a degree that vertical surface displacements of 20-30 mm have been predicted for geodetic sites on the North Sea (Fratepietro et al. 2006).

To get a better idea of the potential impact of unmodeled OBP on surface displacements, we show (Fig. 2) the 12- hourly predicted height effects (again in the center of figure reference frame) due to OBP at St. John's, a city located on the east coast of Newfoundland, Canada, where we might expect to observe large OBP loading effects due to its proximity to the Gulf of St. Lawrence (see Fig. 1). The variations show an annual modulation, achieving maximum negative height amplitudes in the winter. The RMS of the modeled height time series is $2.6 \mathrm{~mm}$. However, frequently larger peak-topeak changes of 10-18 mm over periods of days to weeks are also evident. For comparison, the RMS of GPS reprocessed height residuals [specifically the Massachusetts Institute of Technology (MIT) reprocessed non-linear height residuals to be discussed later in detail] for the GPS station at St. John's is $4.5 \mathrm{~mm}$ (for weekly integrations). The amplitude of the predicted loading effects on vertical surface displacements at St. John's, then, indicates that OBP-driven surface displacements should be large enough at some locations to be observed using geodetic techniques. The associated horizontal surface displacements, are shown in the bottom panel of Fig. 2. These are about a tenth the amplitude of the vertical effects. Given the already small amplitude of the predicted vertical signal, horizontal loading effects will not be discussed in this paper.

van Dam et al. (1997) first looked at the effects of OBP on geodetic station height coordinates using output from an early generation ocean general circulation model (OGCM) driven by the National Meteorological Center's (NMC) daily wind stress and heat flux products (see Chao and Fu 1995). In that study, the authors found that the typical RMS of the predicted heights was around $2 \mathrm{~mm}$ with peak-to-peak variations of about $5 \mathrm{~mm}$. At the time, the authors concluded that the signal was too small to be observed by geodetic techniques. Since then, significant improvements in meteorological forcing models and the resulting OGCMs have been developed. A review of Fig. 1 here demonstrates that the OBP effect determined from the ECCO model is at least $25 \%$ larger in RMS and $100 \%$ larger in the maximum peak-to-peak displacements than the results presented in van Dam et al. (1997). It is impossible to state whether the ECCO model is better than that used in van Dam et al. (1997). However, it is clear that the model is sufficiently different to warrant a reassessment. In addition, improvements in geodetic hardware and data processing techniques have achieved a level of precision such that these small crustal displacements might now be observable in the height coordinate time series of GPS stations.

Recently, several authors have reported on the effect of OBP on regional GPS networks. Nordman et al. (2009) used tide gauge data to estimate non-tidal ocean loading effects on the vertical coordinate of GPS stations on the Baltic sea. The authors found a reduction in scatter in only one of the 3 time series when the correction was applied. The lack of improvement to the GPS time series in that study may be 
Fig. 1 Top-panel

Root-mean-square (RMS) variability of predicted ocean bottom pressure (OBP) surface height displacements for every $2.5^{\circ}$ in latitude and longitude. Results larger than the color scale maximum are deep red. Bottom-panel Absolute (single-epoch) maximum predicted surface displacement over areas of $2.5^{\circ}$ in latitude and longitude. Results larger than the color scale maximum are deep red. Results here were derived in the center-of-figure reference frame
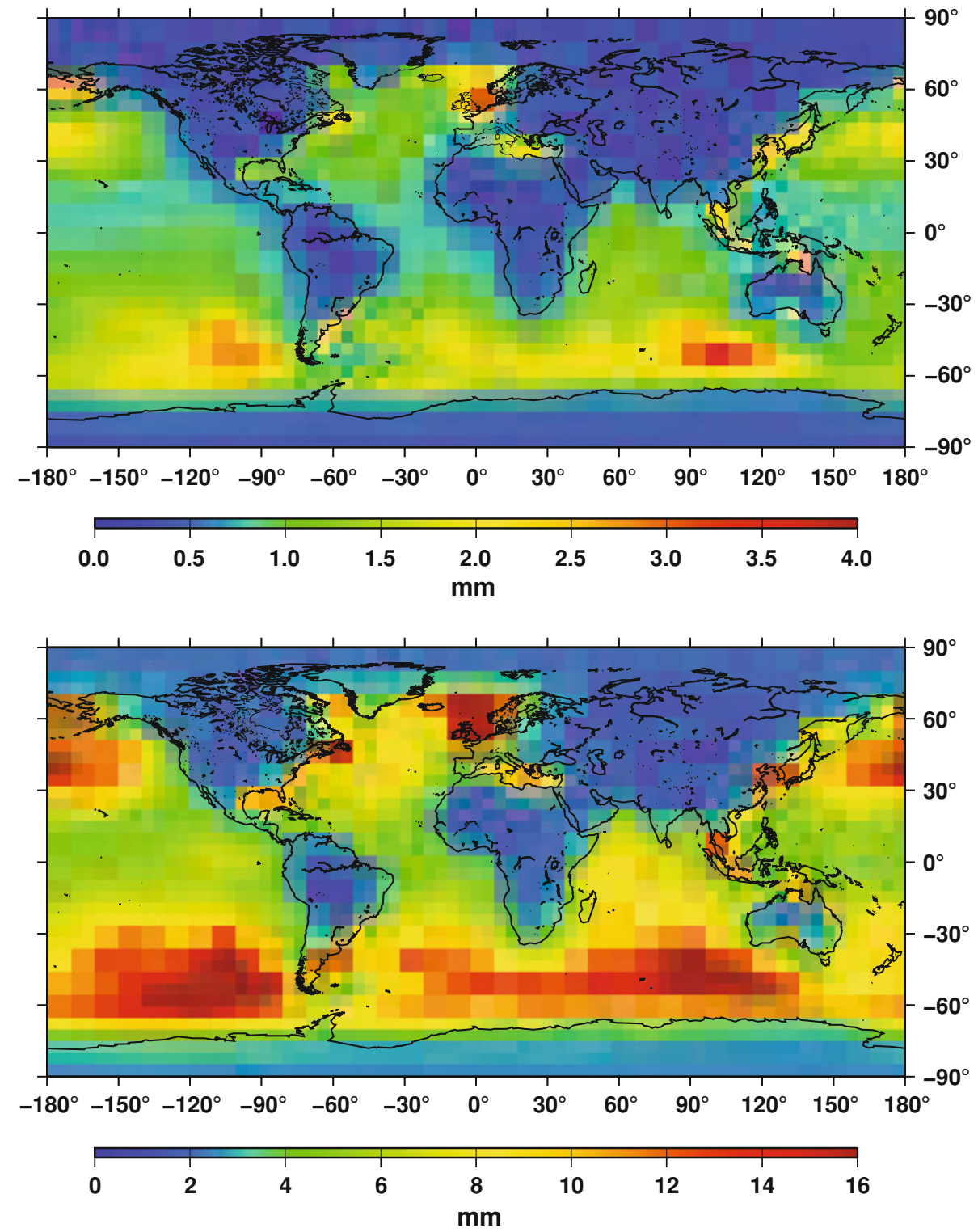

due to the fact that the authors assumed that there were no steric height effects in the tide gauge data. Zerbini et al. (2004) found a $10 \%$ reduction in the scatter of the vertical coordinate (corrected for atmospheric loading) for four GPS sites on the Adriatic Sea when modeled surface displacements due to OBP were removed. They also found that the observed residual height signal and ECCO modeled nontidal ocean loading differed by a factor of 2.5. Munekane and Matsuzaka (2004) investigated the effect at 4 sites in the tropical Pacific. Using sea-level data corrected for steric effects, they found an inverse correlation between sea-level and the GPS vertical coordinates at all sites. Most recently, Williams and Penna (2011) looked at the effect of OBP on height coordinates for 17 GPS sites around the southern North Sea region where the most extreme variations are expected (see Fig. 1). They used the ECCO global model and the high-resolution storm surge model, the Proudman Oceanographic Laboratory Storm Surge Model (POLSSM) for the European continental shelf and found: (1) that in this region, the OBP effects are comparable to the loading caused by the atmosphere, (2) that after removing the atmospheric loading effect from the data, both OBP models reduce the scatter on all the height time series by $20-30 \%$, and (3) except for one site, POLSSM appears to reduce the scatter to a greater extent than ECCO indicating that models derived for a specific region can be more reliable in predicting OBP effects. However, this study fails to provide any insight into the significance of OBP effects at the vast majority of GPS sites located away from such extreme conditions. Also, only 3-4 years of data were used for each of these 17 regional stations.

In this paper, we update the results of van Dam et al. (1997) and estimate the height changes that would be driven by the 
Fig. 2 12-hourly predicted height (top panel) and horizontal surface (bottom panel) displacements (in the center of mass reference frame) at St. John's, Newfoundland, Canada. In the bottom panel, the North-South displacements are in black and the East-West displacements are in transparent red. Note that the $y$-axis for the top panel is a factor of 10 larger than the scale of the bottom panel in this figure

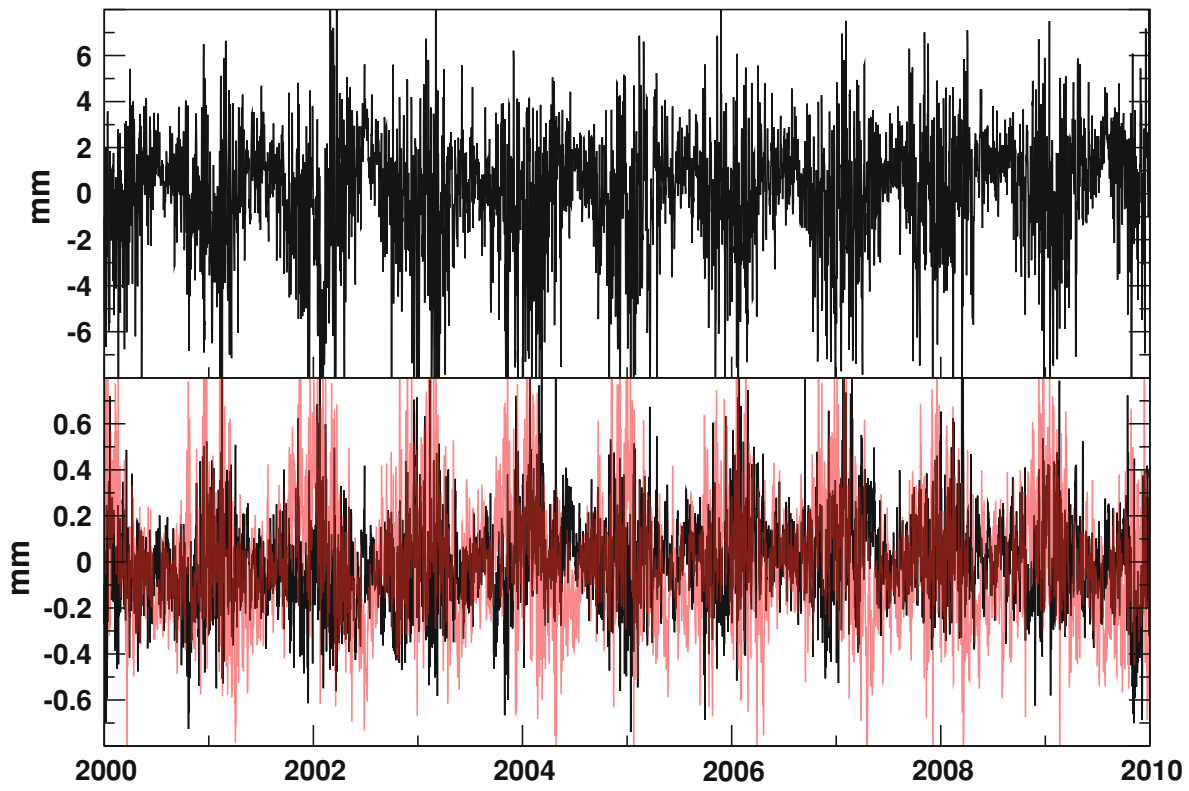

latest ECCO OBP model. We examine the spatial variability of OBP and find that the largest radial displacements of the Earth's surface are expected to be found near semi-enclosed basins. We extend the regional work of the authors described above by comparing observed GPS height time series from a global set of 344 stations with radial surface displacements predicted using the essentially global ECCO OBP model. We use reprocessed non-linear height variations computed at the Massachusetts Institute of Technology (MIT) analysis center as our observational data set, corrected for atmospheric pressure loading.

For the GPS station locations investigated in this paper, we find that the scatter of the predicted OBP height time series is generally small, ranging from a minimum of 0.20 to a maximum of $3.67 \mathrm{~mm}$ in the $\mathrm{CF}$ reference frame. We compare our modeled height effects with GPS height residuals after removing long-term trends. We find that subtracting the model-predicted height variations using the ECCO OBP product reduces the scatter for $70 \%$ of the GPS height time series investigated here. We fit an annual signal to the OBP height changes and remove this signal from the GPS data. We find that the annual component represents about $80 \%$ of the total OBP load effect.

\section{Predicted radial surface displacements}

\subsection{Ocean bottom pressure}

Predicted surface displacements are generated using the ECCO OBP product (http://ecco.jpl.nasa.gov:8080/las-FDS/ LAS/Assimilation_kf_RADS/OBP.info). Specifically, we use the Jet Propulsion Laboratory's Kalman Filter (kf080) series (Fukumori 2002). The model assimilates altimetric sea surface heights, expendable bathythermograph (XBT) profiles, and other ocean in situ data. The OBP is a byproduct of the model for the primary product, that is the general circulation of the ocean driven by winds. The OBP is produced daily for the epochs of 0600 and $1800 \mathrm{~h}$ between $78.5^{\circ} \mathrm{N}$ latitude to $79.5^{\circ} \mathrm{S}$ latitude over the global oceans. Longitudinal spacing is $1^{\circ}$ globally. In latitude, the spacing between the product's northern limit and $20^{\circ}$ of the equator is $1^{\circ}$. The latitudinal spacing is gradually reduced to $0.3^{\circ}$ within $10^{\circ}$ of the equator (For a more in-depth discussion of the ECCO products, the reader is referred to Kim et al. 2007.) The data used here span the 1993-2009 time frame.

At monthly and annual time scales, the ECCO product is in good agreement with estimates of OBP derived from the Gravity Recovery and Climate Experiment (GRACE) satellite mission for locations in the Southern Ocean (Ponte and Quinn 2009; Zlotnicki et al. 2007) and over the global oceans (Chambers and Willis 2008). Another OBP model, driven by the Ocean Model for Circulation and Tides (OMCT) (Thomas 2002), is available from the Deutsches GeoForschungsZentrum, German Research Center for Geosciences. OMCT and ECCO estimates of OBP are based on different models and methodologies (for more information please see Quinn and Ponte 2011). Thus, by comparing surface displacement from both models, and assuming: (1) that the difference between the models is only due to errors in the ECCO model and (2) there are no systematic errors that are common to both data sets, we can place a worst case upper bound on the error in the ECCO data set itself. When we difference heights predicted from both ECCO and OMCT, we find a scatter of $0.7 \mathrm{~mm}$ RMS averaged over our 344 stations, with a maximum scatter of $2.2 \mathrm{~mm}$. Quinn and Ponte (2011) compare the ECCO and OMCT models to each other and to ocean 
bottom pressure recorders (BPRs). They find poor agreement and weak correlations between the models over broad regions most likely driven by the different bottom topography used in each model. They also find that when they compare the model output with the BPRs that the ECCO model can explain more of the observed variance in the BPRs than can OMCT. In a separate analysis, van Dam et al. (2011) compared the RMS improvement/degradation to a set of global GPS height coordinate time series corrected for OBP from ECCO and OMCT. They found that the ECCO OBP was better than the OMCT OBP at reducing the RMS on the GPS height coordinates. This result, like the result of Quinn and Ponte (2011), is expected as ECCO assimilates in situ data into the ocean model whereas OMCT does not. In summary, errors in the ECCO model are extremely difficult to quantify. Nonetheless, they will certainly enter into our estimates of surface displacement. The reader should bear this in mind when considering the statistics.

Initial processing of the ECCO OBP product involves interpolating the data to equally spaced grid points $\left(1^{\circ}\right.$ in latitude and longitude) for each 12-h epoch and removing a mean and a long-term trend from the data. Long-term trends exist in the ECCO OBP data. The trend is caused by the Boussinesq approximation that is used in the model, i.e. oceanic volume, and not mass, is held constant in the OGCM (Ponte et al. 2007). The reader should be aware that real long-term variations in observed OBP are expected due to (1) trends in freshwater fluxes; (2) trends in the atmospheric forcing; and (3) real long-term variations in the large-scale circulation, i.e. long-term climate variability (Chambers et al. 2007). But there is currently no possibility for determining what fraction of the ECCO OBP trends are realistic or not (M. Thomas, personal communication 12/2011). Comparing the GPS trends corrected for all non-OBP secular effects with observed OBP trends derived from GRACE (a pure observation) might be a valuable and insightful exercise. But the problem then arises that we cannot model all non-OBP secular effects in the GPS heights to sufficient precision. For all of these reasons, we focus here on the non-linear variations about a long-term mean.

Surface displacements due to OBP are estimated using the fundamental technique outlined in van Dam and Wahr (1987) for atmospheric pressure loading. Global grids of nontidal ocean mass change are convolved with mass loading Green's functions. In this paper, we use Farrell's Green's functions (Farrell 1972) for a Gutenberg-Bullen Earth model. For the global convolution, OBP surface mass changes over the continents are set to zero. Points over the ocean and outside the $78.5^{\circ} \mathrm{N}-79.5^{\circ} \mathrm{S}$ ECCO data set range are also set to zero. Over the oceans, the $1^{\circ} \times 1^{\circ}$ mass load from the ECCO OBP is used.

Another consideration when modeling surface displacements is the choice of the reference frame for the Green's functions. We must choose a reference frame that is consistent with that of the GPS observations that we will compare with later in the paper. Dong et al. (2003) found that GPS network solutions that have been transformed into the ITRF are, in fact, in a frame that approximates the center of figure $(\mathrm{CF})$ of the Earth (see Blewitt 2003; Dong et al. 2003 for a thorough discussion of the GPS reference frame). To ensure that the surface displacements predicted from the OBP loading will be in the same reference frame as the reprocessed GPS height residuals, we model the displacements using Green's functions appropriate for the CF reference frame.

Figure 3 shows the RMS (top-panel) and maximum height change at each station calculated using data from the entire 17-year period. The results are similar to the results shown in Fig. 1, except that the actual locations of the GPS stations are used in the calculations. The scatter in the heights ranges between 0.20 and $3.67 \mathrm{~mm}$, with an average of $0.76 \mathrm{~mm}$.

Only $8 \%$ of the stations analyzed exhibit a OBP height scatter greater than $1.5 \mathrm{~mm}$; with an average of $2.0 \mathrm{~mm}$. The highest RMS for the predicted height effect is 3.7 for the station WSRT (Westerbork, The Netherlands, near the North Sea). For the remaining stations, the RMS of the predicted OBP height change is small averaging only $0.7 \mathrm{~mm}$ RMS. This amounts to height variations of only $2-3 \mathrm{~mm}$ over a couple of days.

Conversely, for the 26 stations having an RMS greater than $1.5 \mathrm{~mm}$, OBP-induced height changes of between 5 and $10 \mathrm{~mm}$ over a couple of days are frequent. This result can be seen in Fig. 4 where we show 5 years of data for 6 stations representative of this subset of stations: ARP3 (Aransas Pass, Texas, USA, on the Gulf of Mexico), KERG (Port-auxFrançais, Kerguelen Islands in the Southern Indian Ocean), MORP (Morpeth, UK, on the North Sea), RIOG (Rio Grande, on the Southern coast of Argentina), TOW2 (Cape Ferguson, Australia near the Coral Sea), WSTR. The RMS for the 12hourly and weekly predicted vertical displacements for the stations presented in Fig. 4 are provided in Table 1. For these stations, the RMS of the twice-daily predicted heights when averaged into weekly estimates decreases by approximately $22 \%$ on average. If the OBP loading exhibited large subweekly variability, we would expect the RMS to have been reduced even further. This small RMS reduction indicates that most of the variability in the model is at periods longer than a week.

\subsection{Atmospheric pressure loading}

In the next section, we will compare GPS height coordinate observations with the height changes predicted using the ECCO OBP. If real surface height changes due to atmospheric pressure loading are correlated with those height changes due to OBP loading, then our statistics will not reflect the true effect of the OBP loading on GPS heights. 
Fig. 3 Top-panel

Root-mean-square variability of predicted radial surface displacements at locations of the 344 continuously operating GPS stations used in this study. Bottom-panel Maximum predicted radial surface displacement at these sites. Surface displacements were determined using the entire 17 year OBP data set
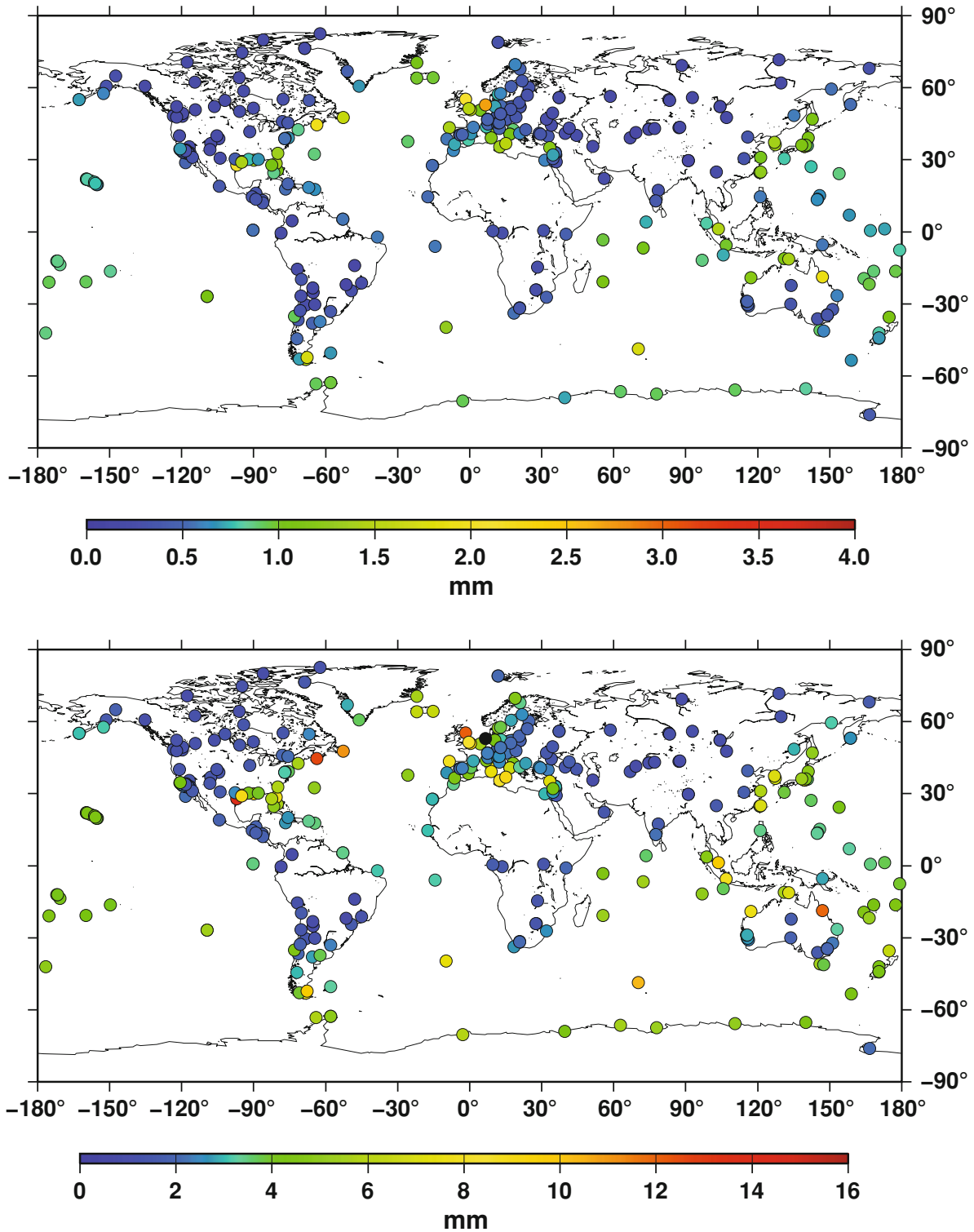

To examine this issue, we determine the correlation between atmospheric pressure loading (ATML) and OBP for our 344 sites. Daily atmospheric loading effects are predicted using a topographic surface pressure data set derived using NCEP surface pressure (van Dam et al. 2010), Farrell's Green's functions, and assuming the ocean response to pressure is a modified inverted barometer (van Dam and Wahr 1987). Like the OBP height changes, the ATML are determined in the $\mathrm{CF}$ reference frame. Correlations range between -0.50 and 0.63 and are shown by the colored symbols in Fig. 5. ATML and OBP are positively correlated at $75 \%$ of the locations investigated. There is a weak correlation between sites with strongly positive ATML-OBP correlations and their proximity to regions of high OBP variability (locations of high OBP variability are shown in the Fig. 1a). However, a number of coastal and islands sites exhibit a negative correlation.
We wish to test if the correlation is significantly different from zero. The probability, $p$, that the correlation should be larger than observed is given by

$p=\operatorname{erfc}\left(\frac{|z| \sqrt{N-3}}{\sqrt{2}}\right)$

where,

$\operatorname{erfc}(x) \equiv \frac{2}{\sqrt{\pi}} \int_{0}^{x} \mathrm{e}^{-x^{2}} \mathrm{~d} t$

is the complementary error function, $N$ is the number of data points and

$z=\frac{1}{2} \ln \frac{1+r}{1-r}$ 
Fig. 4 12-hourly (black) and weekly (red) predicted height coordinate changes for 6 locations with an RMS greater than $1.5 \mathrm{~mm}$ in modeled height. Top-row, left to right: ARP3, KERG, MORP; Bottom-row, left to right: RIOG, TOW2, WSRT. All results here are in the center-of-figure reference frame
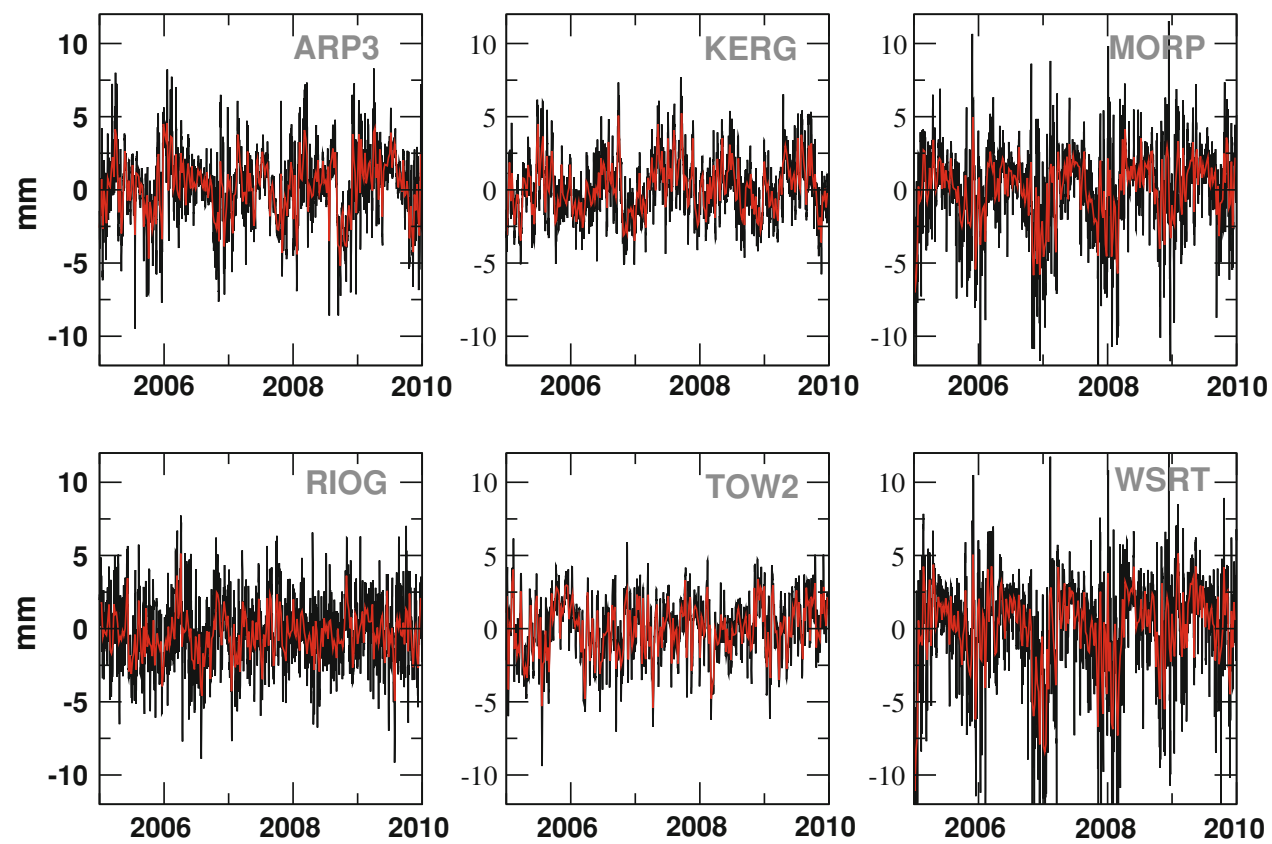

Table 1 RMS of 12-hourly and weekly predicted vertical displacements for the stations highlighted in Fig. 4

\begin{tabular}{llll}
\hline Station & $\begin{array}{l}\text { 12-hourly } \\
\text { RMS (mm) }\end{array}$ & $\begin{array}{l}\text { Weekly } \\
\text { RMS }(\mathrm{mm})\end{array}$ & $\begin{array}{l}\text { Percent RMS } \\
\text { reduction (\%) }\end{array}$ \\
\hline ARP3 & 2.5 & 2.0 & 20 \\
KERG & 2.0 & 1.7 & 15 \\
MORP & 2.8 & 2.1 & 25 \\
RIOG & 2.2 & 1.7 & 23 \\
ROW2 & 2.3 & 1.8 & 22 \\
WSRT & 3.7 & 2.7 & 29 \\
\hline
\end{tabular}

is Fisher's $z$ transformation to associate each measured $r$ with a corresponding $z$ (Press et al. 1992). When we compare the correlation values against the probability from Equation 1, we find that correlations greater than $|0.10|$ have a less than $1 \%$ probability of occurring randomly. For correlations less than $|0.10|$ the probability increases exponentially. For example, a correlation $|0.05|$ has a $20 \%$ probability of occurring randomly. In Fig. 5, the sites with correlations having a probability of less than $1 \%$ are shown as circles; correlations with a probability greater than $1 \%$ are shown as diamonds. Of the original 344 stations, $55 \%$ are positively correlated with a $1 \%$ chance of the correlation occurring randomly; $60 \%$ are positively correlated with a $20 \%$ chance of the correlation occurring randomly.

Williams and Penna (2011) found that the scatter in their predicted height changes due to ATML tended to be of the same order of magnitude as that for the OBP effects for about half the sites that they looked at in the North Sea. The variance of the ATML and OBP at our two sites in that region, HERS (Hailsham, UK) and MORP (Morpeth, UK), are also somewhat comparable. However, when we compare the ATML and OBP signal at all our sites, we find that on average the RMS of the OBP is only $15 \%$ the RMS of the ATML.

One final comment, one might expect that the correlation between ATML and OBP would increase with increasing percentage of ocean surrounding a site. We compare the correlations with the percentage of ocean within $500 \mathrm{~km}$ of each site (not shown). We do not find any relationship between the percentage of ocean surrounding a site and the correlation between ATML and OBP.

\section{Observed height time series}

We compare OBP-predicted height changes with observed GPS height residuals from the MIT reprocessed solution, mil. We chose the mil solution for this analysis because: (1) it is in the public domain; (2) it provided homogeneously preprocessed position time series for 700 globally distributed stations from 1998 to the present; (3) it was used in the International GNSS Service's reprocessing campaign (see http://acc.igs.org/reproldiscretionary-cess.html); and (4) it is an excellent data set that dominates the IGS combined reprocessing from 11 analysis center contributions (Ferland 2010). The mi1 processing strategy is summarized in Table 2. Some aspects of the IGS (and mi1) modeling choices might be questioned, especially the tropospheric mapping function and a 
Fig. 5 Correlation between predicted OBP and ATML for stations analyzed in this paper. Circles show locations where the correlation has a less than $1 \%$ probability of occurring randomly; diamonds are sites where the probability is greater than $1 \%$

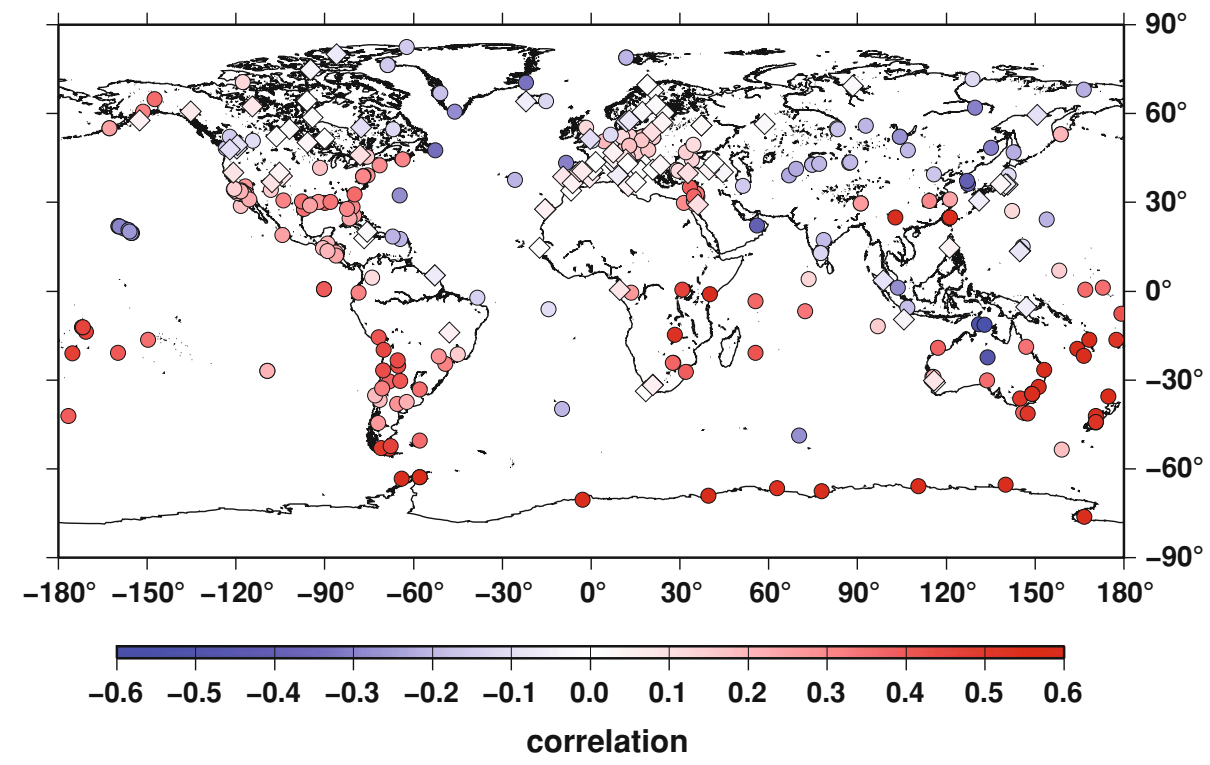

Table 2 MIT GPS data processing strategy summary

\begin{tabular}{|c|c|}
\hline Observables & $\begin{array}{l}\text { Doubly differenced ionosphere-free } \\
\text { combination of L1 and L } 2 \text { carrier phases }\end{array}$ \\
\hline $\begin{array}{l}\text { Ground and satellite } \\
\text { antenna phase centers }\end{array}$ & From (igs05_wwww.atx) \\
\hline $\begin{array}{l}\text { Troposphere a priori } \\
\text { model }\end{array}$ & $\begin{array}{l}\text { Zenith delay: (Saastamoinen 1972) "dry" } \\
\text { + "wet" using Global Pressure and } \\
\text { Temperature (GPT) model from Boehm } \\
\text { et al. (2007) Mapping function: GMF } \\
\text { (Boehm et al. 2006) for dry and wet } \\
\text { zenith delays individually }\end{array}$ \\
\hline \multirow[t]{2}{*}{ Elevation cutoff } & $10^{\circ}$ \\
\hline & $\begin{array}{l}\text { Elevation weighting: } a^{2}+\left(b^{2} / \sin ^{2}(\mathrm{e})\right) \\
\text { with } a, b \text { from site residuals }\end{array}$ \\
\hline \multirow[t]{4}{*}{ Tidal model } & Solid Earth tide: IERS 2003 \\
\hline & Solid Earth pole tide: IERS 2003 \\
\hline & $\begin{array}{l}\text { Ocean tide loading: IERS Conventions } \\
2003 \text { in CM frame }\end{array}$ \\
\hline & $\begin{array}{l}\text { No atmospheric tides nor oceanic pole } \\
\text { tide }\end{array}$ \\
\hline \multirow[t]{2}{*}{ Non-tidal loading effects } & Not applied \\
\hline & $\begin{array}{l}\text { No atmospheric pressure, no surface } \\
\text { hydrology, no ocean bottom pressure }\end{array}$ \\
\hline Ambiguity & $\begin{array}{l}\text { Fixed in about } 95 \% \text { of cases in the recent } \\
\text { years }\end{array}$ \\
\hline
\end{tabular}

priori zenith delays for which more advanced models are available. The potential impacts of these differences will be presented in Sect. 4.

To compute non-linear residuals, long-term positions and velocities are determined for all the stations, taking care to identify and account for all discontinuities in the position time series and modeled in the estimated long-term frame. Since we are interested in the non-linear coordinate variations, the secular reference frame of the long-term coordinates is arbitrarily defined by means of internal constraints (Altamimi et al. 2007). Then, the transformation parameters (translation and rotations) are estimated between each weekly solution and the estimated secular coordinates of the epoch using a subset of well distributed stations in order to minimize aliasing errors (Collilieux et al. 2012). Finally, we estimate the coordinate residuals about the long-term trend by additionally removing the transformation parameters. The procedure is defined in this way in order to provide GPS height displacements as close as possible to residual displacements in the CF frame.

To compare our loading estimates with the weekly GPS residuals, we compute 7-day averages from our 12-hourly predictions centered on each GPS week. Averaging the data into weekly intervals reduces the RMS by about $20 \%$ on average. (See the results presented in Table 1 above.)

At this point, we are ready to compare our modeled OBP weekly height changes with those observed in the GPS data. As discussed in the previous section, we want to ensure that the resulting statistics reflect the influence of only the OPB load model on the GPS heights. If ATML is correlated with OBP and ATML is not removed from the GPS data, then the statistics will not reflect the true OBP-GPS relationship. Thus, we remove the topographic ATML signals from the GPS heights before comparing with the OBP signal. We find that removing the ATML increases the RMS on 89 of the 344 or $25 \%$ of the stations.

In Fig. 6, we show the correlations between the predicted OBP heights with the GPS residuals corrected for ATML. Using the probability function above, we find that positive correlations greater than 0.1 are statistically significant at the $1 \%$ level. 175 of the 344 global stations demonstrate a positive correlation $(>0.1)$ between the OBP-predicted and 
Fig. 6 Correlation between predicted OBP heights with GPS height residuals (topographic ATML removed). Correlations with a $1 \%$ probability of occurring randomly are represented by circles; those with a greater than $1 \%$ probability are plotted as diamonds

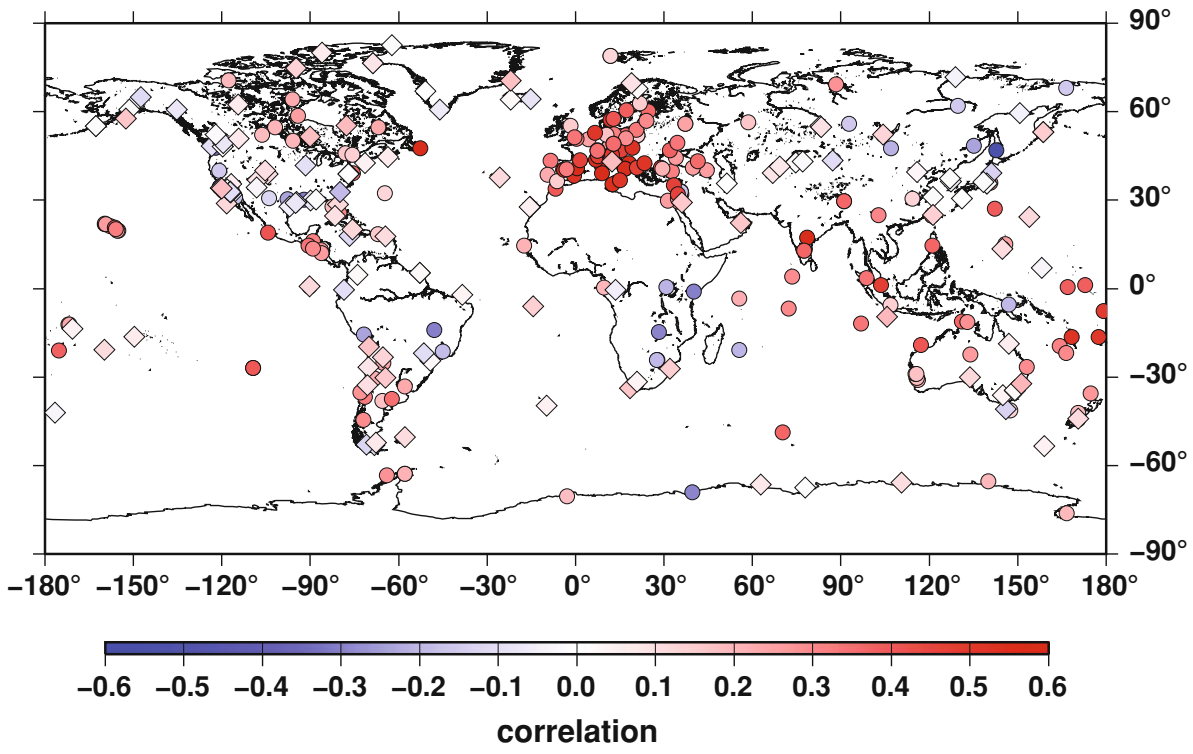

GPS-observed heights at the $1 \%$ significance level. These sites are shown as circles in Fig. 6. For most sites near regions of high OBP variability (see Fig. 1a), the signals are more positively correlated than at other locations. Sites in Europe display the highest correlations of all, presumably due to the large OBP signal predicted for the North and the Mediterranean Seas.

In Fig. 7, we compare the GPS height residuals with ATML removed (red) with the predicted OBP height displacements (black) for 12 sites. The top two rows are the coastal sites shown in Fig. 4. These are sites where the RMS of the predicted height variations are greater than $2 \mathrm{~mm}$. The bottom two rows represent sites located more inland: ALGO (Algonquin Park, Canada, 200 km inland); FAIR (Fairbanks, Alaska, USA, $320 \mathrm{~km}$ inland); ALIC (Alice Springs, Australia, $600 \mathrm{~km}$ inland); LHAS (Lhasa, China, 3,600 km inland); UNSA (Salta, Argentina, 1,200 km inland); WTZA (Bad Koetzting, Germany, $670 \mathrm{~km}$ inland). In all cases, the scatter in the GPS observations is much larger than the predicted effects due to OBP loading. The difference in the amplitude of the predicted and observed scatter in height is less pronounced for the coastal sites. However, the correlation between the GPS and OBP even for the inland sites is moderately large. As a final note on Fig. 7, the correlations between the predicted and observed heights for most sites, excluding ARP3 and FAIR are positive with a high probability of being statistically significant.

In the next step of the analysis, we want to determine if removing the predicted OBP loading signal from the GPS observations reduces the scatter on the height time series. We find that removing the predicted OBP loading height change from the GPS heights reduces the scatter on 223 of the 344 time series investigated. This represents about $65 \%$ of the stations. The largest RMS reduction, $0.65 \mathrm{~mm}$, occurs at NTUS (Singapore, Republic of Singapore). The largest RMS increase, $-0.63 \mathrm{~mm}$, occurs at the coastal station YSSK (Yuzhno-Sakhalinsk, Russian Federation). The RMS reduction for all stations is shown in Fig. 8. The top panel of that figure shows the original RMS of the GPS heights less the topographic ATML. The bottom panel shows the change in RMS, $\mathrm{RMS}_{\mathrm{GPS}}-\mathrm{RMS}_{\mathrm{GPS}-\mathrm{OBP}}$. The median change in RMS over all stations is $0.05 \mathrm{~mm}$.

The proportion of stations where the RMS is decreasing (65\%) is large given that only $8 \%$ of the stations have an RMS for the predicted OBP heights greater than $1.5 \mathrm{~mm}$. Thus, even though the OBP signal is small at most of the stations, the ECCO OBP product must be accurately capturing a large portion of the true load.

The RMS reduction that we observe on the global scale is much less than that observed by Williams and Penna (2011) for their stations in the North Sea. Some of the difference is probably due to the fact that the OBP loading in the North Sea is the largest seen anywhere except perhaps in the Southern Ocean, where only a handful of GPS stations exist. (This issue will be explored in more detail in Sect. 4.)

The results presented in this section indicate that surface displacements due to OBP loading introduce a measurable signal into the GPS observations of height changes. By removing OBP loading effects, determined using the ECCO OBP model, we are able to reduce the scatter on $65 \%$ of the GPS stations (after previously removing ATML loads).

\section{Seasonal signals}

Many authors have investigated the annual signal observed in GPS height coordinate series. Half or a bit more of the observed annual signal is driven by seasonal variations in 
Fig. 7 Comparison of predicted height changes (black) with observed GPS height residuals (ATML removed) (red). Top-row, left to right: ARP3, KERG, MORP; Second-row, left to right: RIOG, TOW2, WSRT; Third-row, left to right: ALGO, FAIR, ALIC, Bottom-row, left to right: LHAS, UNSA, WTZA. The correlation between the GPS and OBP is shown in the bottom left of each plot; the scatter of the OBP signal is shown in the bottom right
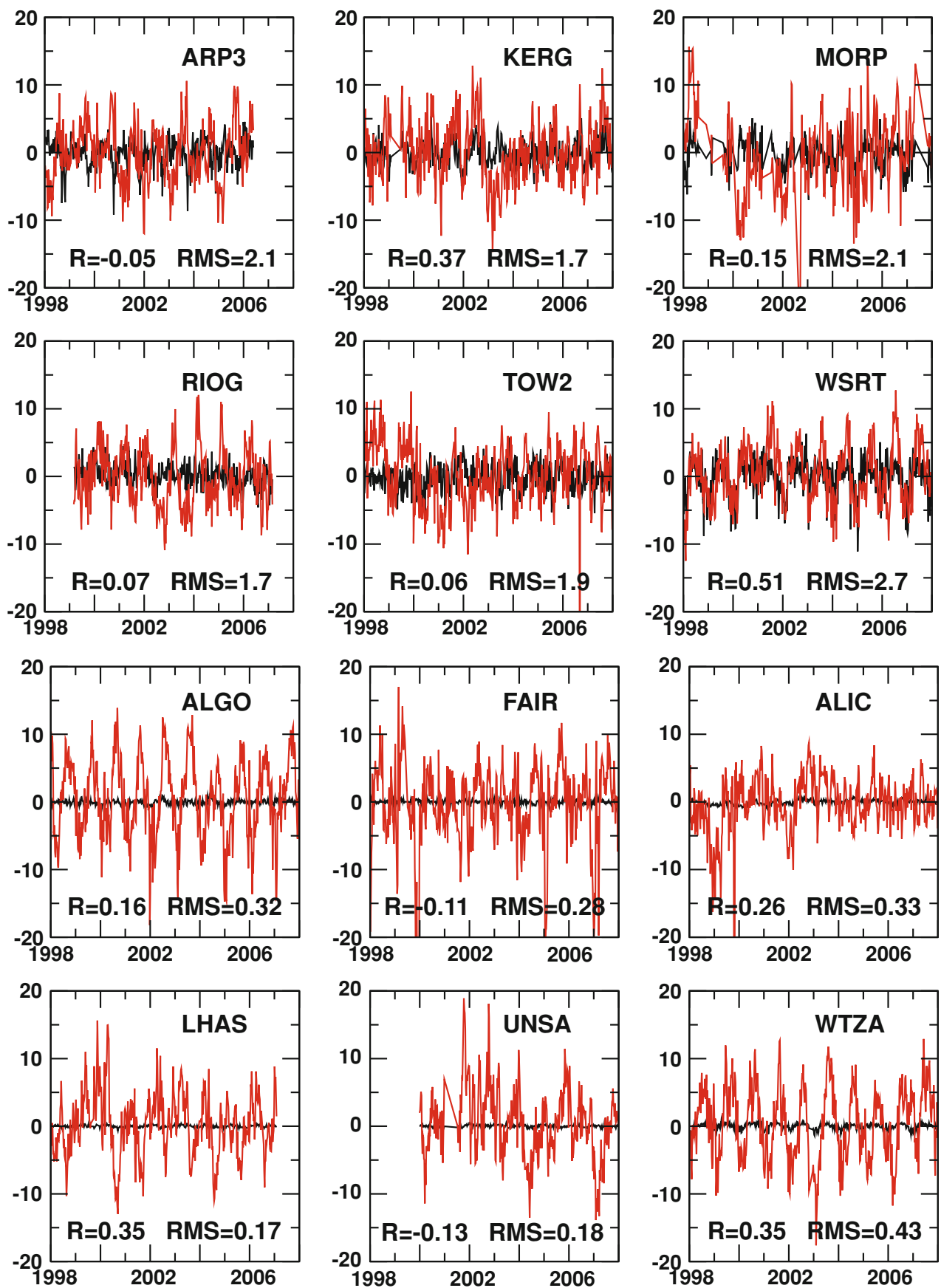

environmental surface loads (see, for example, Dong et al. 2002; Tregoning et al. 2009; Davis et al. 2004; Blewitt et al. 2001; Kusche and Schrama 2005; Horwath et al. 2010; Wu et al. 2006; van Dam et al. 2007, etc.). Thermal deformation of the GPS monuments and the bedrock to which they are attached probably also contribute an annual signal (Dong et al. 2002; Yan et al. 2009). However, technique errors and inaccurate background models used in GPS data processing can also introduce spurious annual signals into the time series (Penna et al. 2007; Steigenberger et al. 2009; Tregoning and
Watson 2009, 2011). Improvements in modeling the annual surface mass loading signal might allow us to sort out issues associated with the imperfect background models used in GPS data processing.

Figure 7 indicates that there is an annual signal in most of the OBP-predicted heights shown. We fit an annual signal to the OBP heights and then remove this fitted OBP annual signal from the GPS heights. We find that we are able to reduce the RMS on the same set of stations where we were able to reduce the RMS when we removed the total signal. 
Fig. 8 Top Panel RMS of GPS heights after correcting for ATML but before correcting for OBP loading; Bottom Panel $\mathrm{RMS}_{\mathrm{GPS}}-\mathrm{RMS}_{\mathrm{GPS}-\mathrm{OBP}}$
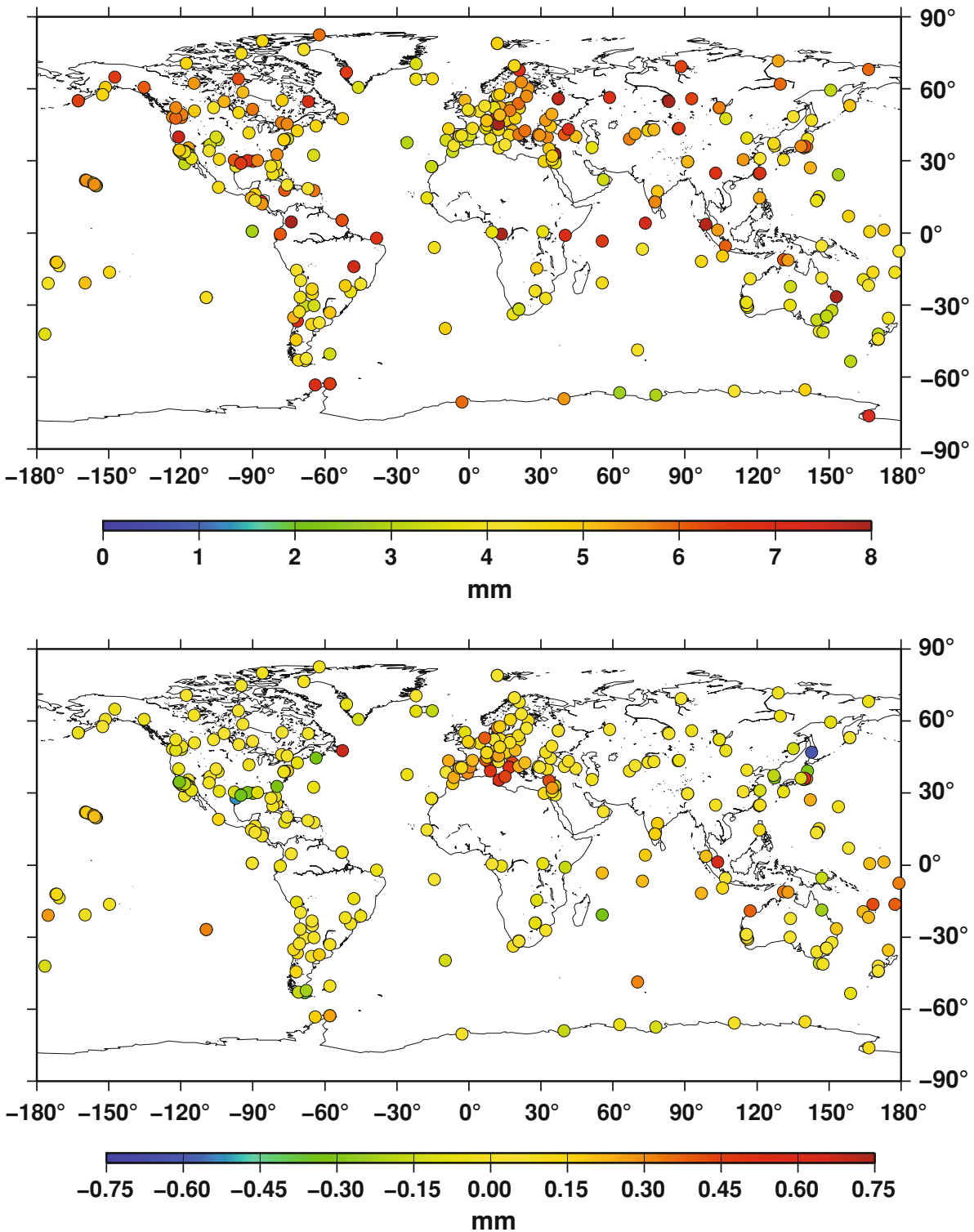

The RMS reduction for the annual signal alone is about $80 \%$ of the total RMS reduction, indicating that most of the power in the OBP data is at annual frequencies.

\section{Discussion and conclusions}

If one is interested in interpreting the long-term trends using GPS height coordinates due to postglacial rebound, sea-level rise, the build up of tectonic strain or even real trends in OBP due to: (1) increasing or decreasing freshwater fluxes; (2) trends in the atmospheric forcing; and (3) real long-term variations in the large-scale circulation, the noise introduced into a time series by short-period environmental mass loading can be significant. The error bar on a trend derived from
GPS coordinate time series is a function of the data sampling, length of the time series, and the noise processes that characterize the data (Williams 2003). One way to reduce the uncertainty in the trend is with longer observation times. Reducing the noise on the data used for determining the long-term trend by removing loading signals allows one to determine a reliable trend with fewer observations. Short-period changes in ocean bottom pressure loading is one such signal that can add unwanted noise, particularly at annual frequencies, to a GPS height coordinate time series.

The only previous quasi-global analysis of the OBP used now outdated models for estimating the loading (van Dam et al. 1997). The results presented here demonstrate that the OBP effect determined from the ECCO model is at least $25 \%$ larger in RMS and $100 \%$ larger in the maximum peak-to-peak predicted height displacements than the results 
presented in van Dam et al. (1997), thus justifying this modern reanalysis with the best "global" data set available. Here we find that the scatter in the ECCO derived OBP heights range between 0.20 and $3.67 \mathrm{~mm}$, at a similar level as the precision of GPS height coordinate observations.

Recent analyses of the OBP effect in GPS heights have been entirely regional in character (Nordman et al. 2009; Zerbini et al. 2004; Munekane and Matsuzaka 2004; Williams and Penna 2011). The analyses by Zerbini et al. (2004) and Munekane and Matsuzaka (2004) used GPS data from stations that were not analyzed here [excluding MEDI (Medicina, Italy)] making it difficult to compare our results with theirs. Two stations used in the Nordman et al. (2009) study were analyzed here. Instead of using an OBP model, they used tide gauge data from the Baltic sea as a proxy for the OBP. The results from the 3 stations that were closely examined [METS (Kirkkonummi, Finland), MAR6 (Maartsbo, Sweden), VIS0 (Visby, Sweden)] demonstrate that they were only able to reduce the RMS on one station and that ATML increases the RMS at all stations. Steric bottom pressure changes were ignored in their analysis, however Virtanen et al. (2010) using the OMCT model demonstrate that this assumption for the Baltic is valid. Nordman et al. (2009) also ignore the influence of OBP changes in the surrounding North Sea that could contribute a loading signal to their GPS height coordinates. In contrast to their results, we find that we are able to reduce the scatter at METS and MAR6 using the ECCO OBP estimates. The RMS at these sites increases when we subsequently correct for ATML.

Williams and Penna (2011) found that the scatter was improved on all 17 of their sites in the southern North Sea region, when ECCO OBP effects (and no ATML) were removed from their GPS heights. We also analyze two stations in the North Sea region, HERS (Halisham, UK) and MORP (Morpeth, UK), though these were not analyzed by Williams and Penna (2011). HERS is on the south coast of the UK facing the English Channel, not the North Sea like the Williams and Penna (2011) stations. Our station MORP is in nearly the same location as their station NEWC (Newcastle). Removing the OBP signal from the GPS heights (not corrected for ATML), we reduce the RMS at MORP by $0.01 \mathrm{~mm}$. Converting to variance change our reduction is still much smaller than the effects of OBP found by Williams and Penna (2011).

Williams and Penna (2011) also found increased RMS reduction at their sites when they removed the ATML as well as OBP. To investigate this effect globally, we compare the OBP and topographic ATML height changes (Fig. 5). We find that often the highest correlations between OBP and ATML do not necessarily correspond to regions of the high OBP variability (Compare the South-western Pacific, the North Sea, and the Mediterranean Sea regions in Figs. 5 and 1). Further, when we focus on our stations in the North Sea, we find that removing the predicted topographic atmospheric corrections increases the scatter at MORP. The variance change for NEWC (the nearest station to MORP in our analysis) from Williams and Penna (2011) is $1.3 \mathrm{~mm}^{2}$, the smallest variance in their set of stations analyzed. NEWC is the farthest point in the northwest part of their network and where the OBP effect is intrinsically small. It is possible that even a relatively short distance away from the coast could make a difference in the RMS between MORP and NEWC, especially if MORP is further inland.

The differences between the results reported here and those of Williams and Penna (2011) are difficult to interpret as there are no subset of stations that overlap between our analyses. Our weaker RMS improvements from this region may arise due to differences in the GPS analyses used in each study (to be discussed below). However, the difference may also be attributed to the different stations analyzed, their much shorter data span, lack of topographic corrections in the ATML corrections, or other possible reasons.

Despite the marginal correlation between OBP and topographic ATML over the globe $(55 \%$ have a positive correlation greater than 0.1 with a $1 \%$ chance that the correlation could occur randomly; $60 \%$ have a positive correlation greater than 0.05 with a $20 \%$ chance that the correlation could occur randomly), we remove the topographic ATML signal from the GPS heights. We do this to ensure that when we compare our GPS heights with the OBP-predicted effects that the statistics do not include the effect of the ATML at sites where OBP and ATML are positively correlated. We find that we are not able to reduce the RMS on all the GPS time series; in $25 \%$ of the cases the RMS increases when we remove the ATML.

To explore the global results further, we determine the correlation between the weekly mil GPS reprocessed height residuals (corrected for ATML) and OBP. We find positive correlations at 175 sites (Fig. 6). The highest correlations are often but not necessarily located near regions of high OBP variability (compare with Fig. 1), in particular notice the stations in the Pacific to the north-east of Australia. Moderately positive correlations are also found in northern North America. This inland correlation is most likely due to the annual signal in the OBP heights. When the OBP-gridded mass fields are decomposed into spherical harmonics and we analyze the power, we find that the annual signal has power over all degrees (not shown). These low degree loads would contribute to land motion at inland sites.

We find that when we remove the predicted OBP heights from the GPS residuals we are able to reduce the scatter on about $65 \%$ of the stations investigated. By modeling the annual signal and removing that from the GPS heights we find that the annual signal accounts for about $80 \%$ of this RMS reduction. The RMS improvement over all sites is shown in the bottom panel of Fig. 8. The biggest improvements are 
for sites in the Mediterranean Sea region and those to the north-east of Australia. These statistical results indicate that ECCO's OBP product is very good at capturing real changes in bottom pressure loading. We conclude that if one wants to reduce the scatter on the GPS height time series to better interpret small trends in the surface deformation (e.g. post-glacial rebound), the ECCO model would be reasonably effective for this purpose. For areas where high-resolution and highprecision ocean dynamic models are available, better results will no doubt be obtained.

We would like to comment on the fact that the mil GPS data that we used in this analysis differs from that used in Williams and Penna (2011) and thus may not optimize the comparison between the predicted OBP and observed station height coordinates. We chose the mil solution for its completeness, because it was used in the International GNSS Service's reprocessing campaign, and because it is an excellent data set when compared to any other publicly available global GPS solutions.

There are mainly three effects that have not been considered in the mil analysis regarding the most up-to-date processing strategies: (1) the mapping function, the Global Mapping Function (GMF) versus the Vienna Mapping Function (Boehm et al. 2006) VMF1; (2) the a priori hydrostatic delay model, output from Global Pressure and Temperature (GPT) model Boehm et al. (2007) versus output from the European Center for Medium Range Weather Forecast (ECMWF); and (3) no atmospheric tidal loading. To get a more precise order of magnitude of the first two effects, Steigenberger et al. (2009) supplied the differences of the annual signals between GMF/GPT with that from a solution that used ECMWF/VMF1. As can be seen from Figure 2 of the Steigenberger et al. paper, the difference of the annual signal in their computation reaches a maximum of about $1.0 \mathrm{~mm}$. The geographic distribution of those differences is starkly distinct from our map of OBP variability except possibly along coastal Antarctica (Fig. 3). However, MIT used an elevation weighting different from that of Steigenberger et al. (2009) [ $\cos ^{2}$ (elevation)] and a higher cutoff angle $\left(10^{\circ}\right.$ vs. $\left.3^{\circ}\right)$. According to the results of Tregoning and Herring (2006), the dilution ratio of the error related to the a priori ZHD error between $10^{\circ}$ and $3^{\circ}$ is about 4 times smaller. The effect of the mapping function error is also attenuated for the same reason. Further, the tropospheric modeling effects only impact our OBP results to the extent that ATML is correlated, which as we have shown, is less by another factor of two or more. As a result, we think that this error is well below the millimeter level in the mil solution. It is true that the OBP loads that we are analyzing are also at this amplitude level, but we expect that the mapping function error and the OBP effects are minimally correlated with one another and that this omission in the data processing will not have an impact on the results presented here.
Another limitation of the mil solution used here is that it does not model tidal atmospheric loading. Tregoning and Watson (2009) studied the impact of neglecting this particular effect. They found that the S2 tidal signal aliased into signals with a period of 174.5 days with an amplitude smaller than $0.2 \mathrm{~mm}$ with the largest effect between the latitude of $-30^{\circ}$ and $30^{\circ}$ (see their correction, Tregoning and Watson 2011). This area corresponds with the limits of the S2 maximum amplitude. A smaller signal at 350 days is also detected with the other part of the spectrum being more "white". The dominant signal is rather close to the semi-annual period. There is no clear evidence in our Fig. 6, showing the correlation between OBP and GPS, that a smaller correlation exists for sites between $-30^{\circ}$ and $30^{\circ}$. The effect seems more geographically located, like in the West of Africa and the West of South America. The correlation is not smaller in Indonesia, for example. So we conclude that even if this effect exists, it is rather small and would not affect our conclusions.

As this paper is meant to present the order of magnitude of the OBP effects over the globe, we feel that the mil data set is more than sufficient for the comparison presented. Nonetheless, we acknowledge that it might be valuable to perform an in-depth comparison of mi1 with a GPS analysis that uses ECMWF/VMF1 and applies atmospheric tidal loading to compare the results specifically with respect to their sensitivity to environmental loading effects.

Based on their analysis of data from the North Sea region Williams and Penna (2011) speculate that to maximize the geophysical signal from GPS height coordinates, particularly for sites located near shallow seas such as the North Sea, that OBP loading effects should be considered. Our global analysis confirms that the modeled OBP loading is indeed largest in shallow constricted seas as suggested by Williams and Penna (2011). However, our analysis also demonstrates that reasonable correlations between the OBP load signal and GPS heights are not restricted to these enclosed bays. Reasonable correlations and RMS reductions of the scatter are also observed at many coastal, island, and inland sites located some distance from maximum OBP loading effects.

Open Access This article is distributed under the terms of the Creative Commons Attribution License which permits any use, distribution, and reproduction in any medium, provided the original author(s) and the source are credited.

\section{References}

Altamimi Z, Collilieux X, Legrand J, Garayt B, Boucher C (2007) ITRF2005: a new release of the International Terrestrial Reference Frame based on time series of station positions and Earth orientation parameters. J Geophys Res 112. doi:10.1029/2007JB004949

Blewitt G (2003) Self-consistency in reference frames, geocenter definition, and surface loading of the solid Earth. J Geophys Res 108. doi: $10.1029 / 2002 J B 002082$ 
Blewitt G, Lavallée D, Clarke P, Nurudinov K (2001) A new global model of Earth deformation: seasonal cycle detected. Science 294:2342-2345

Blewitt G, Altamimi Z, Davis J, Gross R, Kuo C-Y, Lemoine F, Moore A, Neilan R, Plag H-P, Rothacher M, Shum CK, Sideris M, Schšne T, Tregoning P, Zerbini S (2010) Geodetic observations and global reference frame contributions to understanding sea-level rise and variability, chap 9. In: Church J, Woodworth P, Aarup T, Wilson $\mathrm{S}$ (eds) Understanding sea-level rise and variability. Wiley-Blackwell, Sussex

Boehm J, Niell AE, Tregoning P, Schuh H (2006) The global mapping function (GMF): a new empirical mapping function based on data from numerical weather model data. Geophys Res Lett 33. doi:10. 1029/2005GL025546

Boehm J, Heinkelmann R, Schuh H (2007) Short note: a global model of pressure and temperature for geodetic applications. J Geod 81 . doi:10.1007/s00190-007-0135-3

Chambers D, Willis J (2008) Analysis of large-scale ocean bottom pressure variability in the North Pacific. J Geophys Res 113. doi:10. 1029/2008JC004930

Chambers DP, Wahr J, Nerem RS (2004) Preliminary observations of global ocean mass variations with GRACE. Geophys Res Lett 31:L13310. doi:10.1029/2004GL020461

Chambers DP, Tamisiea ME, Nerem RS, Ries JC (2007) Effects of ice melting on GRACE observations of ocean mass trends. Geophys Res Lett 34:L05610. doi:10.1029/2006GL029171

Chang W-L, Smith RB, Wicks C, Farrell JM, Puskas CM (2007) Accelerated uplift and magmatic intrusion of the Yellowstone Caldera, 2004 to 2006. Science 318. doi:10.1126/science. 1146842

Chao Y, Fu L-L (1995) A comparison between the TOPEX/POSEIDON data and a global ocean circulation model during 1992-1993. J Geophys Res 100:24965-24976

Collilieux X, van Dam T, Ray J, Coulot D, Métivier L, Altamimi Z (2012) Strategies to mitigate aliasing of loading signals while estimating GPS frame parameters. J Geod 86:1-14. doi:10.1007/ s00190-011-0487-6

Davis J, Elosegui P, Mitrovica J, Tamisiea M (2004) Climate-driven deformation of the solid Earth from GRACE and GPS. Geophys Res Lett 31. doi:10.1029/2004GL021435

Dong D, Fang P, Bock Y, Cheng MK, Miyazaki S (2002) Anatomy of apparent seasonal variations from GPS-derived site position time series. J Geophys Res 107. doi:10.1029/2001JB000573

Dong D, Yunck T, Heflin M (2003) Origin of the international terrestrial reference frame. J Geophys Res 108:2200. doi:10.1029/ 2002JB002035

Farrell WE (1972) Deformation of the Earth by surface loads. Rev Geophys Spac Phys 10(3):751-797

Ferland R (2010) Combination of the reprocessed IGS Analysis Center SINEX solutions. Paper presentation at IGS 2010 Workshop, Newcastle upon Tyne, UK 30 June 2010

Fratepietro F, Baker TF, Williams SDP, Van Camp M (2006) Ocean loading deformations caused by storm surges on the northwest European shelf. Geophys Res Lett 33:L06317. doi:10.1029/ 2005GL025475

Fukumori I. (2002) A partitioned Kalman filter and smoother. Mon Weather Rev 130:1370-1383

Horwath M, Rülke A, Fritsche M, Dietrich R (2010) Mass variation signals in GRACE products and in crustal deformations from GPS: a comparison. In: Flechtner F, Gruber T, Güntner A, Mandea M, Rothacher M, Schöne T, Wickert J (eds) System Earth via geodeticgeophysical space techniques, advanced technologies in Earth Sciences. Springer, Berlin. ISBN:978-3-642-10227-1

Ji KH, Herring TA (2011) Transient signal detection using GPS measurements: transient inflation at Akutan volcano, Alaska, during early 2008. Geophys Res Lett 38:L06307. doi:10.1029/ 2011GL046904
Khan SA, Liu L, Wahr J, Howat I, Joughin I, van Dam T, Fleming K (2010a) GPS measurements of crustal uplift near Jakobshavn Isbrae due to glacial ice mass loss. J Geophys Res 115:B09405. doi:10.1029/2010JB007490

Khan S, Wahr J, Bevis M, Velicogna I, Kendrick E (2010b) Spread of ice mass loss into northwest Greenland observed by GRACE and GPS. Geophys Res Lett 37. doi:10.1029/2010GL042460

Kim SB, Lee T, Fukumori I (2007) Mechanisms controlling the interannual variation of mixed layer temperature averaged over the Nio-3 Region. J Clim 20:3822-3843. doi:10.1175/JCLI4206.1

King M, Altamimi Z, Boehm J, Bos M, Dach R, Elosegui P, Fund F, Hernandez-Pajares M, Lavalée D, Mendes Cerveira PJ, Penna N, Riva R, Steigenberger P, van Dam T, Vituari L, Williams S, Willis P (2010) Constraints on models of glacial isostatic adjustment: a review of the contribution of ground-based geodetic observations. Surv Geophys 31(5):465-507. doi:10.1007/s10712-010-9100-4

Kusche J, Schrama EJO (2005) Surface mass redistribution inversion from global GPS deformation and gravity recovery and climate experiment (GRACE) gravity data. J Geophys Res 110. doi:10. 1029/2004JB003556

Lavallée DA, Moore P, Clarke PJ, Petrie EJ, van Dam T, King MA (2010) J2: an evaluation of new estimates from GPS, GRACE, and load models compared to SLR. Geophys Res Lett 37. doi:10.1029/ 2010GL045229

Munekane H, Matsuzaka S (2004) Nontidal ocean mass loading detected by GPS observations in the tropical Pacific region. Geophys Res Lett 31. doi:10.1029/2004GL019773

Nordman M, Mäkinen J, Virtanen H, Johansson J, Bilker-Koivula M, Virtanen J (2009) Crustal loading in vertical GPS time series in Fennoscanndia. J Geodyn 48. doi:10.1016/j.jog.2009.09.003

Penna NT, King MA, Stewart MP (2007) GPS height time series: short period origins of spurious long period signals. J Geophys Res 111. doi:10.1029/2005JB004047

Petit G, Luzum B (eds) (2010) IERS conventions 2010. IERS technical note, 36. Verlag des Bundesamts für Kartographie und GeodŠsie, Frankfurt am Main. Paperback, in print

Petrov L, Boy JP (2004) Study of the atmospheric pressure loading signal in very long baseline interferometry observations. J Geophys Res 109. doi:10.1029/2003JB002500

Ponte RM (1999) A preliminary model study of the large-scale seasonal cycle in bottom pressure over the global ocean. J Geophys Res 104. doi:10.1029/1998JC900028

Ponte R, Quinn K (2009) Bottom pressure changes around Antarctica and wind-driven meridional flows. Geophys Res Lett 36. doi:10. 1029/2009GL039060

Ponte R, Quinn K, Wunsch C, Heimbach P (2007) A comparison of model and GRACE estimates of the large-scale seasonal cycle in ocean bottom pressure. Geophys Res Lett 34. doi:10.1029/ 2007GL029599

Press WH, Teukolsky SA, Vetterling WT, Flannery BP (1992) Numerical recipes in Fortran 77, vol 1, 2nd edn. Cambridge University Press, Cambridge

Quinn KJ, Ponte RM (2011) Estimating high frequency ocean bottom pressure variability. Geophys Res Lett 38. doi:10.1029/ 2010GL046537

Saastamoinen J (1972) Atmospheric correction for the troposphere and stratosphere in radio ranging of satellites. The use of artificial satellites for geodesy. American Geophysics Union, Geophys Monogr Ser 15:247251

Scherneck H-G, Johansson JM, Koivula H, van Dam T, Davis JL (2002) Vertical crustal motion observed in the BIFROST project. J Geodyn 35:425-441

Schuh H, Easterman G, Cretaux J-F, Berge-Nguyen M, van Dam T (2003) Investigation of hydrological and atmospheric loading by space geodetic techniques. In: Hwang C, Shum C-K, Li JC (eds) IAG Symposia, 126. International Workshop on Satellite Altimetry 
for Geodesy, Geophysics and Oceanography. Springer, Berlin, pp 123-132

Steigenberger P, Boehm J, Tesmer V (2009) Comparison of GMF/GPT with VMF1/ECMWF and implications for atmospheric loading. J Geod 83. doi:10.1007/s00190-009-0311-8

Stepanov VN, Hughes CW (2006) Propagation of signals in basin-scale ocean bottom pressure from a barotropic model. J Geophys Res 111:C12002. doi:10.1029/2005JC003450

Tesmer V, Steigenberger P, van Dam T, Mayer-Gurr T (2011) Vertical deformations from homogeneously processed GRACE and global GPS long-term series. J Geod 85. doi:10.1007/ s00190-010-0437-8

Thomas M (2002) Ocean induced variations of Earth's rotation-results from a simultaneous model of global circulation and tides. PhD dissertation, University of Hamburg, Germany

Tizzani P, Berardino P, Casu F, Euillades P, Manzo M, Ricciardi GP, Zeni G, Lanari R (2007) Surface deformation of Long Valley caldera and Mono Basin, California, investigated with the SBAS-InSAR approach. Remote Sens Envirn 108. doi:10.1016/j.rse.2006. 11.015

Tregoning P, Herring T.A (2006) Impact of a priori zenith hydrostatic delay errors on GPS estimates of station heights and zenith total delays. Geophys Res Lett 33. doi:10.1029/2006GL027706

Tregoning P, Watson C (2009) Atmospheric effects and spurious signals in GPS analyses. J Geophys Res 114:B09403. doi:10.1029/ 2009JB006344

Tregoning P, Watson C (2011) Correction to "Atmospheric effects and spurious signals in GPS analyses". J Geophys Res 116:B02412. doi:10.1029/2010JB008157

Tregoning $\mathrm{P}$, Watson C, Ramillien G, McQueen H, Zhang J (2009) Detecting hydrologic deformation using GRACE and GPS. Geophys Res Lett 36:L15401. doi:10.1029/2009GL038718

van Dam TM, Herring TA (1994) Detection of atmospheric pressure loading using very long baseline interferometry measurements. J Geophys Res 99:4505-4518

van Dam TM, Wahr J (1987) Displacements of the Earth's surface due to atmospheric loading: effects on gravity and baseline measurements. J Geophys Res 92:1281-1286

van Dam TM, Blewitt G, Heflin M (1994) Detection of atmospheric pressure loading using the global positioning system. J Geophys Res 99:23,939-23,950

van Dam TM, Wahr J, Chao Y, Leuliette E (1997) Predictions of crustal deformation and of geoid and sea-level variability caused by oceanic and atmospheric loading. Geophys J Int 129:507-517 van Dam T, Wahr J, Milly PCD, Shmakin AB, Blewitt G, Lavallée D, Larson K et al (2001) Crustal displacements due to continental water loading. Geophys Res Lett 28:651-654

van Dam T, Wahr J, Lavallée D (2007) A comparison of annual vertical crustal displacements from GPS and gravity recovery and climate experiment (GRACE) over Europe. J Geophys Res 112:B03404. doi:10.1029/2006JB004335

van Dam T, Altamimi Z, Collilieux X, Ray J (2010) Topographically induced height errors in predicted atmospheric loading effects. J Geophys Res 115:B07415. doi:10.1029/2009JB006810

van Dam TM, Collilieux X, Rebischung P, Ray J, Altamimi Z (2011) Quantifying load model errors by comparison to a global GPS time series solution. Abstract, Fall American Geophysical Union, San Francisco

Virtanen J, Mäkinen J, Bilker-Koivula M, Virtanen H, Nordman M, Kangas A, Johansson M, Shum CK, Lee H, Wang L, Thomas M (2010) Baltic sea mass variations from GRACE: Comparison with in situ modelled sea level heights. In: Mertikas M (ed) Gravity, geoid and Earth observation. International Association of Geodesy Symposia 135. Springer, Berlin, pp 571-577. doi:0.1007/ 978-3-642-10634-7_76

Williams S (2003) The effect of coloured noise on the uncertainties of rates estimated from geodetic time series. J Geod 76:483-494. doi:10.1007/s00190-002-0283-4

Williams SDP, Penna NT (2011) Non-tidal ocean loading effects on geodetic GPS heights. Geophys Res Lett 38:L09314. doi:10.1029/ 2011GL046940

Wu X, Heflin MB, Ivins ER, Fukumori I (2006) Seasonal and interannual global surface mass variations from multisatellite geodetic data. J Geophys Res 111. doi:10.1029/2005JB004100

Yan H, Chen W, Zhu Y, Zhan W, Zhong M (2009) Contributions of thermal expansion of monuments and nearby bedrock to observed GPS height changes. Geophys Res Lett 36. doi:10.1029/ 2009GL038152

Zerbini S, Richter B, Negusini M, Romagnoli C, Simon D, Domenichini F, Schwahn W (2004) Height and gravity variations by continuous GPS, gravity and environmental parameter observations in the southern Po Plain, near Bologna, Italy. Earth Planet Sci Lett 192( 267-279):192-267279

Zlotnicki V, Wahr J, Fukumori I, Song Y (2007) Antarctic Circumpolar Current Transport Variability during 2003-05 from GRACE. J Phys Oceanogr 37. doi:10.1175/JPO3009.1 